\title{
Wheat Leaf Rust Uredospore Production on Adult Plants: Influence of Leaf Nitrogen Content and Septoria tritici Blotch
}

\author{
Corinne Robert, Marie-Odile Bancal, and Christian Lannou
}

First and second authors: INRA Environnement et Grandes Cultures, BP 01, 78850 Thiverval Grignon, France; and third author: INRA Pathologie Végétale, BP 01, 78850 Thiverval Grignon, France.

Accepted for publication 3 February 2004

\section{ABSTRACT}

Robert, C., Bancal, M. O., and Lannou, C. 2004. Wheat leaf rust uredospore production on adult plants: Influence of leaf nitrogen content and Septoria tritici blotch. Phytopathology 94:712-721.

Leaf rust uredospore production and lesion size were measured on flag leaves of adult wheat plants in a glasshouse for different lesion densities. We estimated the spore weight produced per square centimeter of infected leaf, per lesion, and per unit of sporulating area. Three levels of fertilization were applied to the plants to obtain different nitrogen content for the inoculated leaves. In a fourth treatment, we evaluated the effect of Septoria tritici blotch on leaf rust uredospore production. The nitrogen and carbon content of the spores was unaffected or marginally affected by lesion density, host leaf nitrogen content, or the presence of Mycosphaerella graminicola on the same leaf. In leaves with a low-nitrogen content, spore

The timing and abundance of sporulation by pathogens causing polycyclic diseases, such as leaf rust, are key factors determining how the disease increases. A precise description of spore production and the factors affecting rates and patterns of pathogen sporulation is important for understanding epidemic development and predicting yield loss $(3,5,13)$. Studies on spore production have largely focused on density-dependent effects; spore production per lesion varies inversely with the number of lesions on the leaf $(11,15,16,19,23)$. However, other factors also influence spore production. Studies on several pathogens $(14,15,19)$ indicate that interactions between host and pathogen genotypes and environmental factors influence the sporulation capacity of foliar pathogens. It has been established that temperature influences the sporulation rate of Uromyces phaseoli (11) and Puccinia recondita (22), and contradictory results have been found on the effect of relative humidity for $U$. phaseoli $(11,23)$. Cohen and Rotem $(6)$ have shown that light intensity influences the sporulation of several obligate parasites by affecting host photosynthesis. Lastly, leaf age and the plant development stage affect the sporulation capacity of bean and wheat rusts $(11,22)$.

Although it is generally agreed that application of nitrogen fertilizers may influence plant health by altering the susceptibility to plant pathogens, few published reports have shown how host nitrogen status influences pathogen spore production (18). Such information is crucial for the development of integrated pest management systems based on predicting epidemic dynamics in changing agrosystems. The nitrogen inputs for wheat crops vary widely, depending on the production situation and economic constraints. In addition, although leaf rust (P. triticina) is generally

Corresponding author: C. Robert; E-mail address: corinne.robert@bbsrc.ac.uk

Publication no. P-2004-0510-02R

(C) 2004 The American Phytopathological Society production per lesion was reduced, but lesion size was unaffected. A threshold effect of leaf nitrogen content in spore production was however, evident, since production was similar in the medium- and high-fertilizer treatments. In leaves inoculated with $M$. graminicola and Puccinia triticina, the rust lesions were smaller and produced fewer spores. The relationships among rust lesion density, lesion size, and uredospore production were fitted to a model. We determined that the density effect on spore production resulted mainly from a reduction in lesion size, the spore production per unit of sporulating surface being largely independent of lesion density. These results are consistent with those obtained previously on wheat seedlings. The main difference was that the sporulation period lasted longer in adult leaves.

Additional keywords: epidemic modeling, pathogen interaction. associated with other pathogens, mainly Mycosphaerella graminicola (anamorph Septoria tritici) in field epidemics, there seems to be no published information about how pathogens on the same host may interact with respect to spore production.

We recently (18) showed that the density of leaf rust lesions on wheat seedlings affects spore production mostly by influencing the lesion size. A high density of lesions results in smaller lesions, but the number of spores produced per unit of sporulating area remains approximately constant at a given temperature. The data also suggested that host nitrogen content affects spore production.

Our objective in the current study was to extend our previous results (18) to adult plants and analyze the way that coinfection by $M$. graminicola and a change in the leaf nitrogen content influence the sporulation capacity of leaf rust. Flag leaves were inoculated with $P$. triticina or $P$. triticina plus $M$. graminicola, and plants were grown with three different fertilization levels.

\section{MATERIALS AND METHODS}

Overview. An experiment was performed in the spring of 2001 in a glasshouse to quantify and model leaf rust uredospore production in adult wheat flag leaves. Three levels of fertilization (N0, N1, and N2) were used to determine whether leaf nitrogen status influences spore production by the fungus. Spore production per lesion and lesion size were modeled as a function of time and lesion density with the data from the N1 (reference) plants. In addition, a set of plants fertilized as N1 was inoculated with $P$. triticina and $M$. graminicola (Septoria tritici blotch [STB]) to evaluate the influence of STB on uredospore production (treatment S). The wheat cv. Soissons was used in all treatments.

Plant material. Seeds were left to germinate for $24 \mathrm{~h}$ in humid cotton and then sown in Jiffy peat pots where they were kept for 8 weeks with a 16 -h light period $\left(350 \mu \mathrm{E} \mathrm{m}^{-2} \mathrm{~s}^{-1}\right)$ at $8^{\circ} \mathrm{C}$ and an 8 -h dark period at $0^{\circ} \mathrm{C}$ for vernalization. They were transferred to 
square pots (1.1 liter), filled with commercial compost (peat substrate, Gebr. Brill Substrate, Georgsdorf, Germany), placed in the glasshouse, and watered daily. Daylight was complemented with sodium lamps from 0800 to $2000 \mathrm{~h}$. The temperature ranged between 8 and $15^{\circ} \mathrm{C}$ during the night and 15 to $30^{\circ} \mathrm{C}$ during the day. Plants were treated against powdery mildew (ethyrimol at $2 \mathrm{ml} /$ liter; Syngenta, St Cyr, France) 3 weeks before inoculation. The day they were placed in the glasshouse, the plants were fertilized with Osmocote (10-11-18 N-P-K). Three fertilizer concentrations were applied as follows: N0 was a low-fertilizer treatment with $2 \mathrm{~g}$ of Osmocote per pot, treatment $\mathrm{N} 1$ received a standard dose of $7 \mathrm{~g}$ per pot, and $\mathrm{N} 2$ was an over-fertilized treatment with $18 \mathrm{~g}$ per pot. The nitrogen content of the flag leaves was measured the day before inoculation and at the end of the experiment. Three chlorophyll-meter measurements (SPAD-502; Minolta Camera Co., Osaka, Japan) were made along each leaf the day before inoculation and the average value $(m)$ was used to estimate the leaf nitrogen content ( $N$ in milligrams of nitrogen per square centimeter) with equation 1

$$
N=0.0233 \times \exp (0.0426 \times m)
$$

Equation 1 was derived from data obtained on 20 flag leaves grown as described above, but fertilized with 0 to $25 \mathrm{~g}$ of Osmocote per pot. The nitrogen and carbon content of each of these 20 leaves was measured by the Dumas method (7). Their nitrogen content was then related to the chlorophyll-meter measurement to obtain equation $1\left(R^{2}=0.91\right)$. Their carbon content was on average $2.30 \mathrm{mg}$ of carbon per $\mathrm{cm}^{2}$ and found independent of the fertilization used $(P=0.15)$. In the absence of a nondestructive method for measuring the carbon content in the inoculated leaves, this latter value was considered to be the carbon content before inoculation for all treatments of our experiment. The control and infected leaves were harvested at the end of the experiment and their fresh weight, dry weight, and carbon and nitrogen contents were measured. The levels of nitrogen and carbon in the leaves were compared among treatments with a 1-factor analysis of variance (ANOVA) (SAS; SAS Institute Inc., Cary, NC), and a Bonferroni test was used for multiple comparisons. All secondary tillers were cut before inoculation. For each treatment, four plants were not inoculated and were used as control healthy plants.

Inoculation. When plants were at growth stage 55 (heading) (24), 162 adult flag leaves of main stems were inoculated with $P$. triticina in a settling tower (8). The number of leaves inoculated per treatment was 48 for N0, 48 for N2, and 66 for N1. A wide range of lesion densities was obtained by inoculating the flag leaves with a mixture of leaf rust uredospores (Isolate B9384-1C1) and talc in which the spore content was 9, 5, 3, 2, 1, or $0.5 \mathrm{mg}$ ( 8 plants of $\mathrm{N} 0$ and $\mathrm{N} 2$ and 11 plants of N1 inoculated per dose). Inoculated plants were incubated for $24 \mathrm{~h}$ at $17^{\circ} \mathrm{C}$ with $100 \%$ relative humidity and then placed in the glasshouse until the end of the experiment.

Among the 66 plants fertilized (N1) and inoculated with $P$. triticina, 25 plants were inoculated again with $M$. graminicola and were referred to as treatment $\mathrm{S}$. This left 41 plants for treatment N1. Leaves were inoculated with $M$. graminicola the day after $P$. triticina inoculation. A single pycnidiospore isolate of $M$. graminicola obtained from a naturally infected Soissons plant was used for all plants. This isolate was increased on potato dextrose agar (PDA) medium in a growth chamber at $18^{\circ} \mathrm{C}$. Spores were collected from 3-day-old cultures in sterile distilled water. The spore suspension was adjusted to $10^{8}$ spores per ml with a hemacytometer, and one drop of surfactant (Tween 20) was added before inoculation. The spore suspension was applied to restricted areas of the leaves with a soft paintbrush. Doubly inoculated plants were incubated 5 days in a walk-in growth chamber with a 16-h light period $\left(350 \mu \mathrm{E} \mu^{-2} \mathrm{~s}^{-1}\right)$ at $18^{\circ} \mathrm{C}$ and an 8 -h dark period at $17^{\circ} \mathrm{C}$ with $100 \%$ relative humidity. Control plants were given the same treatment with no inoculation. For $P$. triticina as well as $M$. graminicola, plants were inoculated in a cabinet separated from the glasshouse to avoid unwanted contaminations. When chlorosis was visible, we selected 17 plants from treatment N1, 16 plants from treatment S, 15 plants from treatment N0, and 11 plants from treatment $\mathrm{N} 2$ to obtain the widest range of lesion densities, with as much as possible, a uniform distribution on the leaves.

Lesion density. The number of lesions per leaf was counted 16 days after inoculation. Because of variation in exposure to spores during inoculation, some of the leaves presented large areas with no lesions toward the basis or the apex. Lesion density effects occur when lesions are sufficiently close to each other. For instance, there is no density effect on seedlings when lesion density is $<4$ lesions per $\mathrm{cm}^{2}$ (18). Thus, taking into account the whole leaf areas for calculating lesion densities (in lesion per square centimeter) would have given unrealistic figures. For leaves presenting nondiseased areas, we therefore, calculated the lesion density relative to the actually infected area plus $1 \mathrm{~cm}$ each side along the leaf length. Lesion distribution on the diseased parts of the leaves was visually homogeneous.

In treatment S, only the leaf area free of STB necrosis was considered for calculating the rust lesion density. The STB lesion area (including sporulating and nonsporulating necrosed areas) was measured by image analysis (Optimas; Media Cybernetics, Silver Spring, MD) at each harvest date.

Spore production. Spore production was estimated by collecting and weighing spores from each inoculated leaf at regular intervals after the onset of sporulation. Before sporulation, leaves were placed horizontally in 10-cm-diameter transparent cellophane tubes (E.M.B.,Versailles, France). The tubes were perforated to provide better temperature and water regulation. Spores were collected every 2 or 3 days by shaking the leaves so the spores fell onto the tubes, from which they were immediately weighed. The precision of our scales was of $\pm 0.001 \mathrm{mg}$.

In treatments $\mathrm{N} 0, \mathrm{~N} 1$, and $\mathrm{N} 2$, approximately $90 \%$ of the lesions began to sporulate 12 days after inoculation. This was considered to be the first sporulation day $(t=1)$, and spores were collected $4,7,9,11,14,16,18,21,23,25,28,32,36,39,43$, and 49 days after the beginning of sporulation. In treatment S, $90 \%$ of the lesions started to sporulate 10 days after inoculation. This shift was certainly because the doubly inoculated plants were kept in a growth chamber for 5 days after STB inoculation, with a better-controlled temperature than in the glasshouse. The spore collection dates and lesion size assessments were the same for all treatments, and the time between onset of rust sporulation and spore collection was 2 days longer for the treatment $\mathrm{S}$ plants (i.e., the first collection date occurred 6 days after the beginning of sporulation, etc.).

In treatment $\mathrm{S}$, we took into account two possible effects of STB lesions on leaf rust. First, because of STB lesion growth, some of the leaf rust lesions overlapped STB lesions and stopped producing spores. This was considered as a direct effect. Second, STB may affect the sporulation capacity of rust lesions located on the green part of the leaves and this was considered as a possible indirect effect. We attempted to distinguish both effects by reevaluating the actual number of sporulating lesions; at each collection date, the number of sporulating lesions was decreased proportionally to the area occupied by STB lesion growth and used to calculate a corrected spore production per lesion. This correction was acceptable since the lesions were homogeneously distributed on the diseased parts of the leaves.

Lesion size. Digital pictures were taken of the leaves of all plants at each spore collection date and were used to estimate the lesion size by image analysis (Optimas; Media Cybernetics). Lesion size was defined as the average sporulating surface area of a lesion.

Although rust lesions became visible 2 days earlier in treatment $\mathrm{S}$, pictures were taken at the same time for all treatments. Lesion 
size was measured on the entire flag leaves at 4, 9, 11, 16, 21, 28, 36 , and 43 days after the onset of sporulation in treatments $\mathrm{N} 1$, $\mathrm{N} 2$, and N0. After day 30, host tissue necrosis made the size assessments less accurate. In treatment $S$, the leaf rust lesion size was evaluated for those parts of the leaves free of STB during the rust sporulation period.

Spore production and lesion size models. The data from treatment $\mathrm{N} 1$ were used to model spore production and lesion size as described in Sache et al. (20) and Robert et al. (18). The relationship between cumulative spore production per lesion $(Y$, in milligrams), lesion age ( $t=$ number of days after onset of sporulation, with $t=1$ for the first sporulation day), and lesion density ( $d=$ number of lesions per square centimeter of leaf) was established in a two-step procedure. Cumulative spore production per lesion at each collection date was first related to lesion density:

$$
\ln \left[Y_{t}(d)\right]=a_{t}-b_{t} \times \ln (d)
$$

For each collection date, $a(t)$ and $b(t)$ were plotted against lesion age $(t)$, and the following equations were fitted to the data between 4 and 49 days after onset of sporulation:

$$
\begin{aligned}
& a(t)=m_{a}-\exp \left(c_{a}-f_{a} \times t\right) \\
& b(t)=m_{b}-\exp \left(c_{b}-f_{b} \times t\right)
\end{aligned}
$$

Parameters $m_{a}$ and $m_{b}$ were estimated by the maximum values $(t=$ 49) of $a(t)$ and $b(t)$, respectively. Parameters $c_{a}, f_{a}, c_{b}$, and $f_{b}$ were estimated by the least square method after $\log$ transformation of equations $3 \mathrm{a}$ and $3 \mathrm{~b}$.

Combining equation $3 \mathrm{a}$ and $\mathrm{b}$ with equation 2 gave an estimate of the cumulative spore production per lesion $(Y$, in milligram per lesion) at day $t$ after onset of sporulation for a lesion density $(d)$ :

$$
Y(t, d)=\exp \left\{m_{a}-\exp \left(c_{a}-f_{a} \times t\right)-\left[m_{b}-\exp \left(c_{b}-f_{b} \times t\right)\right] \times \ln (d)\right\}
$$

Daily spore production per lesion $(P$, in milligrams per day and per lesion) for lesion of age $(t)$ and lesion density $(d)$ was estimated by

$$
P(t, d)=Y(t, d)-Y(t-1, d)
$$

Since this model has been established for lesion densities greater than three lesions per $\mathrm{cm}^{2}$ (18), the parameters were estimated with only 16 leaves of treatment N1 instead of 17.

Lesion growth was modeled as cumulative spore production per lesion (equations 2 to 4 ). Lesion size ( $S$, square millimeter of sporulating area) was related to lesion density $(d)$ and lesion age ( $t$, number of days after onset of sporulation) by

$$
\ln \left[S_{t}(d)\right]=\mathrm{u}_{t}-\mathrm{v}_{t} \times \ln (d)
$$

Parameters $u(t)$ and $v(t)$ were plotted against lesion age $(t)$ as in equation $3 \mathrm{a}$ and $\mathrm{b}$ to finally give an estimate of the sporulating area of individual lesion, $(t)$ days after onset of sporulation, for a lesion density $(d)$ :

$$
S(t, d)=\exp \left\{m_{u}-\exp \left(d_{u}-e_{u} \times t\right)-\left[m_{v}-\exp \left(d_{v}-e_{v} \times t\right)\right] \times \ln (d)\right\}
$$

Data of treatment N1 obtained between 4 and 28 days after onset of sporulation and for lesion densities greater than three lesions per $\mathrm{cm}^{2}$ (16 leaves) were used for the lesion size model estimation. After day 30, lesion size progressively decreased because of lesion necrosis, but this was not taken into account in the model.

Nitrogen and carbon contents of uredospores. For each treatment, the nitrogen and carbon contents of the spores produced by each infected leaf were measured on five collection dates: 9, 14, 21,25 , and 32 days after the onset of sporulation by the Dumas method (7).

Statistical analyses. The different treatments were compared for their effects on cumulative spore production per lesion, lesion size, and nitrogen and carbon content of the spores by covariance analyses, with lesion density as a covariate. Log-transformation was used to linearize the data. For the nitrogen and carbon content, data were arcsine transformed before analysis. Multiple mean comparisons were done with the Tukey test and $\alpha=5 \%$. Specific comparisons between two treatments were done with Ttests $(\alpha=5 \%)$.

The model established with data of treatment N1 (equations 4 and 7) was used to compare the measured values in treatments N0, N2, and S to expected values of treatment N1.

\section{RESULTS}

Nitrogen and carbon contents of leaves. The average nitrogen content of the leaves before inoculation was not significantly different for treatments N0, N1, and S but was significantly higher in N2 (Table 1). At the end of the experiment, leaf nitrogen was significantly lower in treatment N0 relative to that in N1 and N2 but there was no longer any significant difference between N2 and $\mathrm{N} 1$. The difference in leaf nitrogen content between treatments $\mathrm{N} 0$ and $\mathrm{N} 1$ was $0.094 \pm 0.017$ (milligram of nitrogen per square centimeter), (i.e., the leaf nitrogen content was reduced by $54 \%$ in N0, relative to N1). In treatment $\mathrm{S}$, the average nitrogen content of the leaves was lower than in $\mathrm{N} 1$ and $\mathrm{N} 2$, but the difference was significant only for N2.

The carbon content of the leaves before inoculation was considered constant among treatments $\left(2.30 \mathrm{mg}\right.$ of carbon per $\left.\mathrm{cm}^{2}\right)$. However, since nitrogen and carbon contents in the leaves were positively correlated at the end of the experiment (correlation coefficient $=0.750, P=0.000$ ), carbon content in treatment N2 leaves could have been higher than those in N1 and N0. At the

\begin{tabular}{|c|c|c|c|c|c|}
\hline \multirow[b]{2}{*}{ Treatment $^{\mathrm{u}}$} & \multirow[b]{2}{*}{ No. of leaves assessed } & \multicolumn{2}{|c|}{ Nitrogen content } & \multicolumn{2}{|c|}{ Carbon content } \\
\hline & & $\mathrm{T} 1^{\mathrm{v}}$ & $\mathrm{T} 2^{\mathrm{w}}$ & $\mathrm{T} 1^{\mathrm{x}}$ & $\mathrm{T} 2^{\mathrm{y}}$ \\
\hline NO & 15 & $0.183 \mathrm{a}^{\mathrm{z}}$ & $0.081 \mathrm{a}$ & 2.30 & $2.16 \mathrm{~b}$ \\
\hline $\mathrm{N} 2$ & 11 & $0.235 \mathrm{~b}$ & $0.185 \mathrm{c}$ & 2.30 & $2.60 \mathrm{a}$ \\
\hline
\end{tabular}
end of the experiment, the leaf carbon content was significantly lower in treatments N0 and S, relative to N1 and N2 (Table 1).

Rust severity. We did not explicitly measure infection efficiency (number of lesions per inoculated spores), but by inoculating a large number of plants with increasing doses of spores,

TABLE 1. Leaf nitrogen and leaf carbon content (milligrams per square centimeter) before inoculation (T1) and at the end of the sporulation period (T2)

" N0 = low-fertilization level, $\mathrm{N} 1=$ standard-fertilization level, $\mathrm{S}=$ leaves inoculated with Puccinia triticina and Mycosphaerella graminicola and fertilized as

$\mathrm{N} 1$, and $\mathrm{N} 2$ = high-fertilization level.

${ }^{v}$ F-ratio $($ analysis of variance $[$ ANOVA] $)=21.8$, mean square error $(\mathrm{MSE})=0.0003$, and $P$ value $($ ANOVA $)=0.0001$.

${ }^{\mathrm{w}} \mathrm{F}$-ratio $(\mathrm{ANOVA})=55.0, \mathrm{MSE}=0.0006$, and $P$ value $($ ANOVA $)=0.0001$.

${ }^{x}$ Constant value (see Material and Methods).

${ }^{y}$ F-ratio $($ ANOVA $)=24.9$, MSE $=0.0420$, and $P$ value $($ ANOVA $)=0.0001$.

${ }^{\mathrm{z}}$ Figures followed by the same letter are not significantly different $(P=0.05)$. 
we obtained a large range of lesion densities for each fertilization treatment. Lesion density ranged from 9.5 to 41.9 lesions per $\mathrm{cm}^{2}$ in treatment N2, 2.1 to 29.4 lesions per $\mathrm{cm}^{2}$ in N1, and 1.7 to 18.4 lesions per $\mathrm{cm}^{2}$ in N0. Although we used the same range of inoculum doses for each fertilization treatment, the average lesion density in treatment $\mathrm{N} 2$ was higher $(P=0.009)$ than that in $\mathrm{N} 1$ and N0. Lesion density influenced the timing of lesion development only marginally and differences in latency were lower than $24 \mathrm{~h}$, as expected for a highly susceptible cultivar like Soissons.

In treatment $S$, leaf rust lesion density ranged from 1.6 to 28.4 lesions per $\mathrm{cm}^{2}$. When rust started to sporulate, STB severity (expressed as the proportion of leaf area occupied by STB) ranged from 9 to $32 \%$ of the leaf area. Some of the rust lesions were gradually overlapped by STB over the following days, and the number of sporulating leaf rust lesions decreased (Fig. 1). At the end of the sporulation period (51 days after onset of sporulation), the reduction in the number of sporulating leaf rust lesions varied between 32 and 96\%, depending on STB severity and STB lesion distribution on the leaves.

Spore production and lesion size in treatment N1. Spore production per leaf increased with lesion density toward asymptotic values that could represent the maximal production capacity of an infected leaf. The maximal weight of spores produced per leaf reached $184 \mathrm{mg}$. In treatment N1, the overall spore production per square centimeter of infected leaf increased from $1.7 \mathrm{mg} / \mathrm{cm}^{2}$ at a lesion density of 2.1 lesions per $\mathrm{cm}^{2}$ to $5.4 \mathrm{mg} / \mathrm{cm}^{2}$ at a lesion density of 29.4 lesions per $\mathrm{cm}^{2}$ (Fig. 2). Spore production per square centimeter of leaf was lower in N0 and S treatments at all lesion densities, with a maximum spore production approximately $3 \mathrm{mg} / \mathrm{cm}^{2}$ of infected leaf.

During the sporulation period, the cumulative spore production per lesion (Fig. 3) became progressively higher on leaves with lower lesion densities and this density effect increased with time. In treatment $\mathrm{N} 1$, the cumulative spore production per lesion at the end of the sporulation period $(t=49)$ was $0.84 \mathrm{mg} / \mathrm{lesion}$ for the lowest lesion density ( 2.1 lesions per $\mathrm{cm}^{2}$ ), and approximately $0.15 \mathrm{mg} / \mathrm{lesion}$ for the highest densities $\left(>20\right.$ lesions per $\mathrm{cm}^{2}$ ). These figures are similar to those obtained for seedlings of the same cultivar in a previous experiment (18) (Fig. 4).

In treatment $\mathrm{N} 1$, leaf rust lesion growth was strongly affected by lesion density (Fig. 5). The sporulating area of the lesions in-

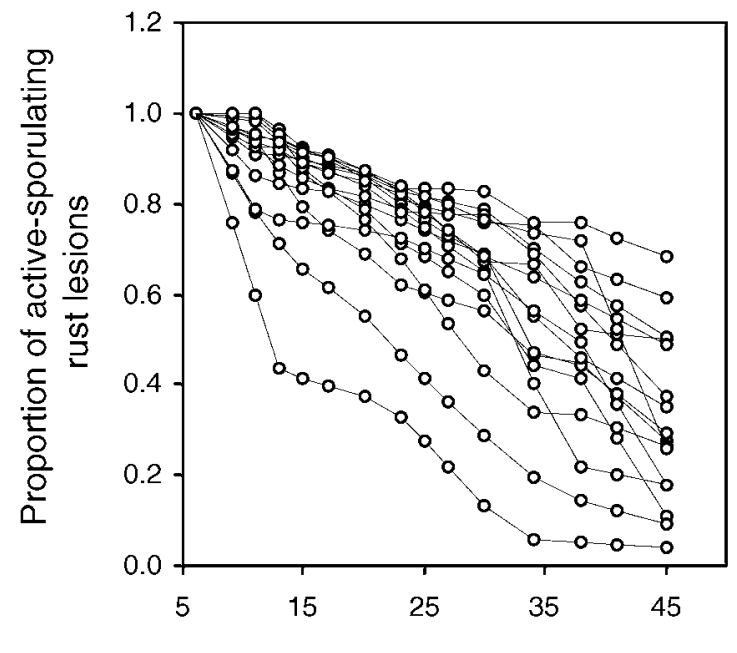

Days after onset of sporulation

Fig. 1. Estimated proportion of sporulating rust lesions in leaves inoculated with Puccinia triticina and Mycosphaerella graminicola (treatment S), plotted against time in days after onset of sporulation. The decrease is mainly due to the growth of Septoria tritici blotch lesions (sporulating and nonsporulating necrosis) overlapping the rust lesions. These figures were used for calculating a corrected spore production per lesion with updated numbers of activesporulating rust lesions. creased until approximately day 20 of sporulation for the highest lesion densities, and day 30 for the lowest densities. The sporulating area decreased thereafter because sporulating tissues became necrotic. The maximal lesion size was $3.4 \mathrm{~mm}^{2}$ (at a density of 2.1 lesions per $\mathrm{cm}^{2}$ ), and the minimal lesion size was $0.48 \mathrm{~mm}^{2}$ (at a density of 21.4 lesions per $\mathrm{cm}^{2}$ ). These spore production and lesion size data are comparable to figures obtained for seedlings in another study (18).

Table 2 indicates the quality of the models estimating spore production and lesion size as a function of lesion density and time. Between days 4 and 11, the relationship between lesion density and cumulative spore production per lesion (equation 2) was poorly explained by the model, but the model fit increased from day $14\left(R^{2}=0.20\right)$ and $R^{2}$ remained above 0.84 between day 28 and day 49. Fitting equation 4, relating cumulative spore production per lesion-to-lesion density and lesion age, we obtained

$$
\begin{aligned}
& Y(t, d)=\exp \{0.691-\exp (2.260-0.083 \times t) \\
& -[0.753-\exp (0.480-0.066 \times t)] \times \ln (d)\}
\end{aligned}
$$

The model fitted the data well (Fig. 4). The $R^{2}$ value between observed and estimated values of spore production was 0.96 (calculated with pooled data for days 4 to 49 ). The residual distribution showed no bias, except on day 4 for low lesion densities, in which equation 4 underestimated spore production.

The relationship between lesion density and lesion size (equation 6) was poorly explained by the model between days 4 and 9 , but the model quality increased at day $11\left(R^{2}=0.24\right)$ and $R^{2}$ remained above 0.70 after day 16 (Table 2 ). Fitting equation 7 , relating sporulating area to lesion density and lesion age, we obtained

$$
\begin{aligned}
& S(t, d)=\exp \{2.617-\exp (1.777-0.077 \times t) \\
& -[0.905-\exp (0.322-0.063 \times t)] \times \ln (d)\}
\end{aligned}
$$

Here again, the model fitted the data well. The $R^{2}$ value between observed and estimated values of spore production was 0.85 (calculated with pooled data for days 4 to 28 ). The residual distribution showed no bias except on day 4 , in which equation 7 slightly overestimated lesion size.

The outputs of the models are given in Figure 6. Cumulative spore production per lesion estimated with equation 4 is shown in

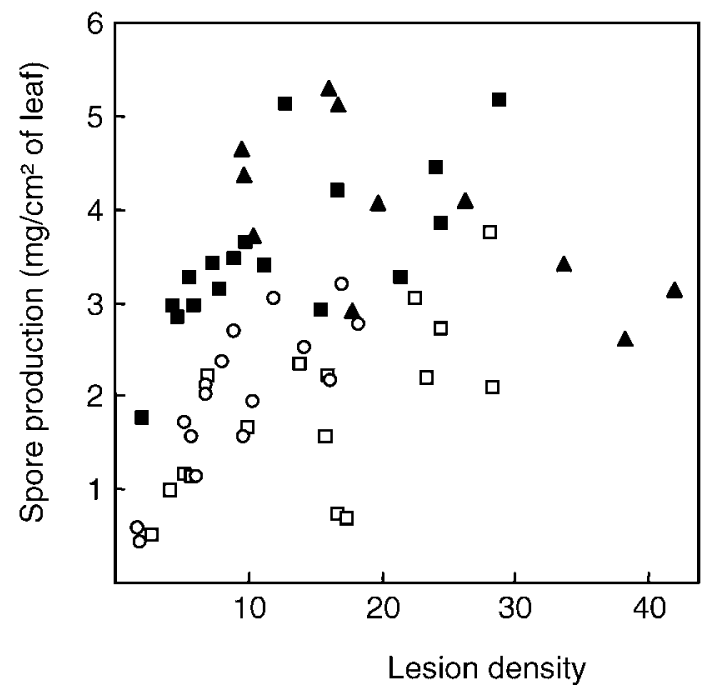

Fig. 2. Weight of spores produced by Puccinia triticina on adult flag leaves of susceptible wheat cv. Soissons plotted against lesion density (lesions per square centimeter). Spore production is in milligrams of spores (fresh weight) per square centimeter of leaf. Four sets of data are shown: N1 plants (standard-fertilization level, solid squares), N2 plants (high-nitrogen level, solid triangles), N0 plants (low-nitrogen level, open circles), and S plants (inoculated with leaf rust and Mycosphaerella graminicola, open squares). 


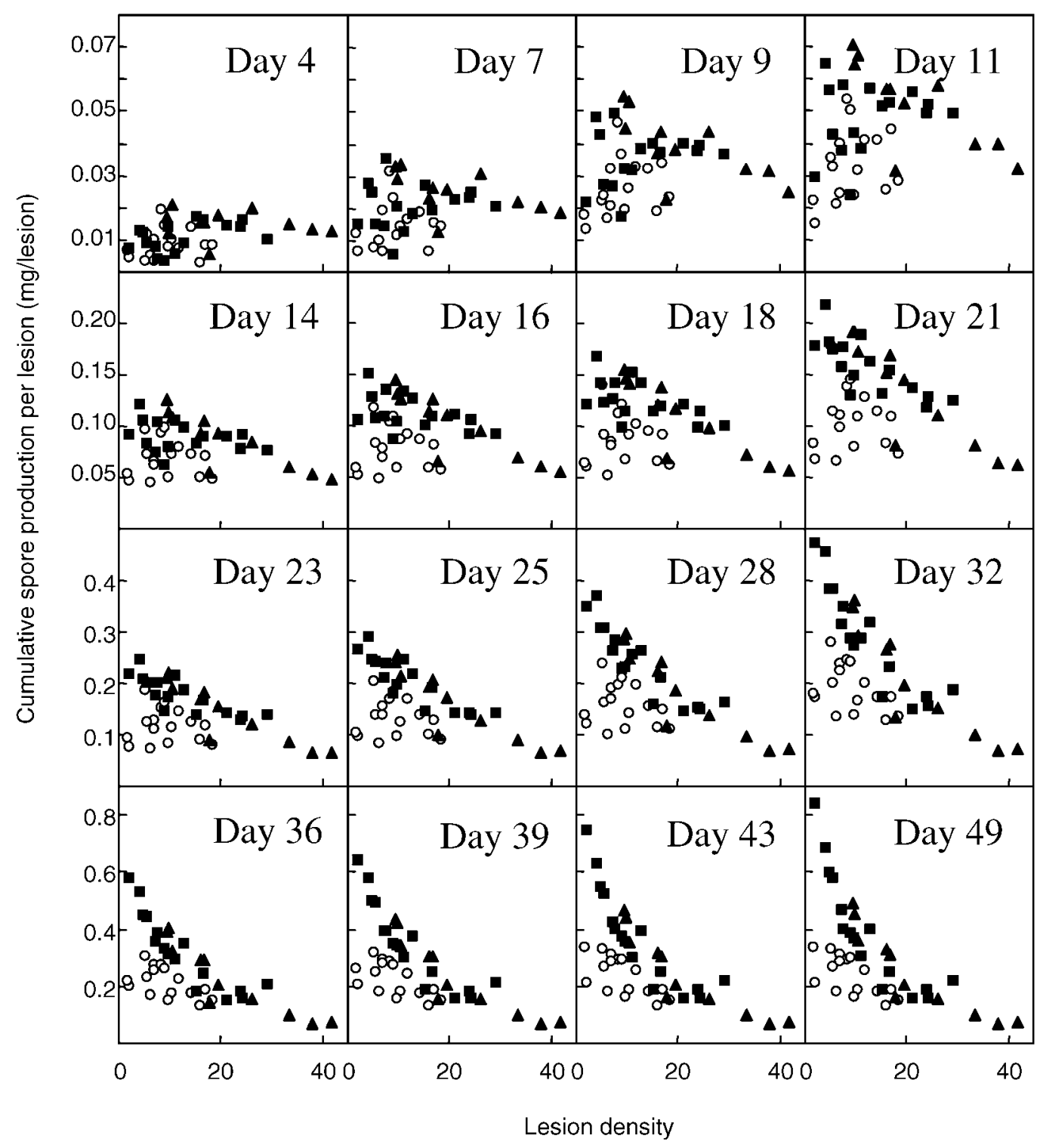

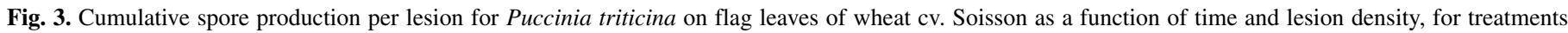

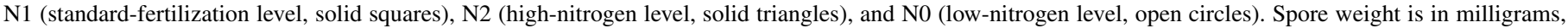
lesion density is in lesions per square centimeter of leaf, and time is in days after the onset of sporulation. Y-axis scale changes after days 11,21 , and 32.

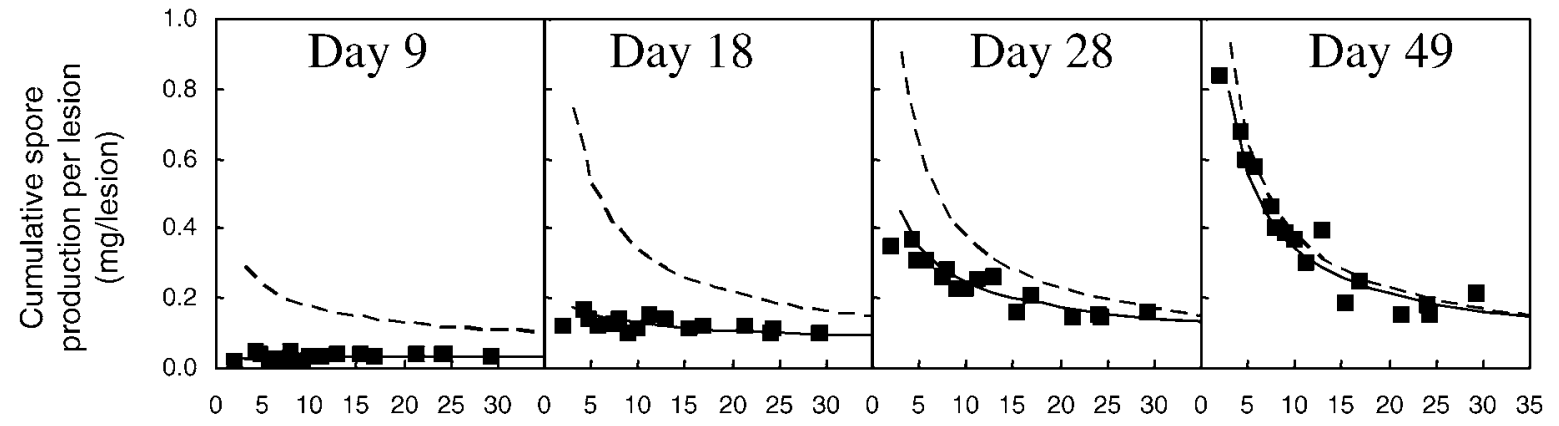

lesion density

Fig. 4. Cumulative spore production per lesion for Puccinia triticina on flag leaves of wheat (cv. Soisson), as a function of time and lesion density, compared with spore production on primary leaves of seedlings. Spore weight is in milligrams, lesion density is in lesions per square centimeter of leaf, and time is in days after onset of sporulation. Data are from N1 (standard-fertilization level) adult plants (squares), continuous lines represent cumulative spore production per lesion as estimated with equation 4 , and dotted lines represent cumulative spore production per lesion estimated for primary leaves of seedlings in a previous experiment (18). 
Figure $6 \mathrm{~B}$. We estimated that $80 \%$ of the spores were produced within 40 days after the beginning of sporulation, at a density of 3 lesions per $\mathrm{cm}^{2}$, and within 23 days at a density of 30 lesions per $\mathrm{cm}^{2}$.

Daily spore production per lesion, calculated from equation 5 , (Fig. 6C) showed an asymmetric bell-shaped curve. The length of the sporulation period and the maximum daily spore production increased, while the date at which the maximum was reached was delayed at smaller lesion densities. The maximum spore production per lesion decreased from $0.028 \mathrm{mg} / \mathrm{lesion} /$ day at a density of
3 lesions per $\mathrm{cm}^{2}$ to $0.008 \mathrm{mg} / \mathrm{lesion} /$ day at 30 lesions per $\mathrm{cm}^{2}$. Spore production per lesion was greatest between 14 days after onset of sporulation (30 lesions per $\mathrm{cm}^{2}$ ) and 24 days after onset of sporulation (3 lesions per $\mathrm{cm}^{2}$ ). Estimated sporulation periods lasted 40 days at a lesion density of 30 lesions per $\mathrm{cm}^{2}$ and over 60 days at a density of 3 lesions per $\mathrm{cm}^{2}$.

Spore production per square millimeter of sporulating area was modeled by dividing the estimated spore production per lesion per day (equation 5; Fig. 6C) by the estimated lesion size (equation 7; Fig. 6A). The strong effect of density on spore production

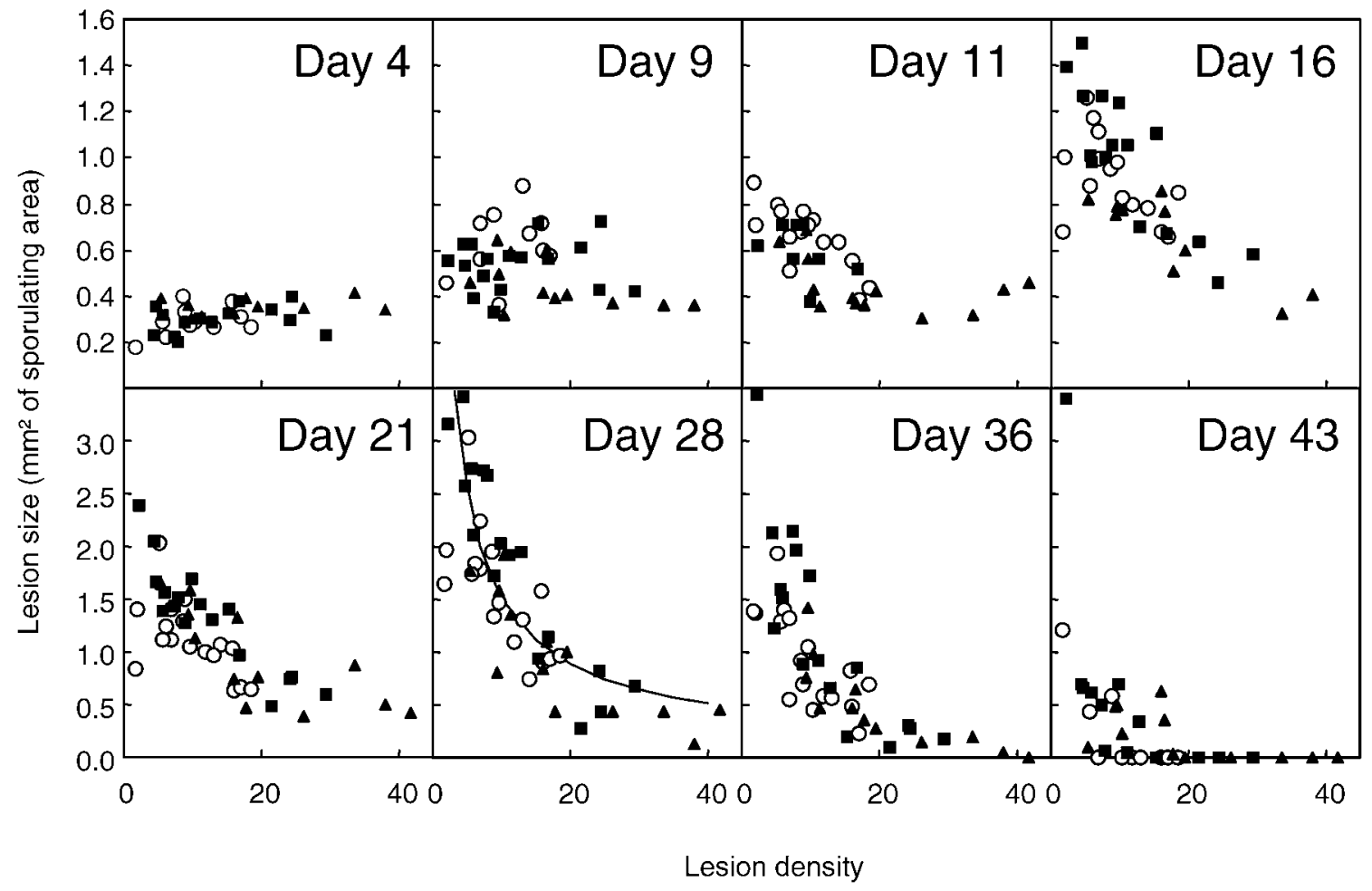

Fig. 5. Leaf rust lesion size (square millimeter) for Puccinia triticina on flag leaves of wheat (cv. Soisson), as a function of lesion density (lesions per square centimeter of leaf) and time in days after the onset of sporulation, for treatments N1 (standard-fertilization level, solid squares), N2 (high-nitrogen level, solid triangles), and N0 (low-nitrogen level, open circles). Lesion size is defined as the sporulating area. The continuous line represents lesion size estimated for primary leaves of seedlings in a previous experiment (18). Y-axis scale changes after day 16.

TABLE 2. Statistics for the cumulative spore production model (equations 2 and 4) and lesion size model (equations 6 and 8) for leaf rust (Puccinia triticina) on wheat flag leaf

\begin{tabular}{|c|c|c|c|c|c|c|c|c|c|c|c|c|c|c|c|c|}
\hline \multirow[b]{2}{*}{ Model } & \multicolumn{16}{|c|}{$t^{\mathrm{u}}$} \\
\hline & 4 & 7 & 9 & 11 & 14 & 16 & 18 & 21 & 23 & 25 & 28 & 32 & 36 & 39 & 43 & 49 \\
\hline \multicolumn{17}{|l|}{ Equation $2^{v}$} \\
\hline$a(t)$ & -4.32 & -3.93 & -3.39 & -2.97 & -2.15 & -1.87 & -1.74 & -1.34 & -1.17 & -0.82 & -0.43 & -0.07 & 0.19 & 0.38 & 0.53 & 0.69 \\
\hline$b(t)$ & -0.04 & -0.03 & -0.03 & -0.01 & 0.10 & 0.10 & 0.13 & 0.15 & 0.22 & 0.34 & 0.44 & 0.53 & 0.60 & 0.66 & 0.70 & 0.75 \\
\hline$R^{2}$ & 0.03 & 0.03 & 0.01 & 0.00 & 0.20 & 0.32 & 0.36 & 0.63 & 0.62 & 0.76 & 0.84 & 0.85 & 0.86 & 0.87 & 0.88 & 0.89 \\
\hline$F$ & 0.12 & 0.40 & 0.15 & 0.01 & 3.3 & 6.1 & 7.4 & 21.9 & 22.9 & 43.4 & 75.4 & 79.9 & 87.6 & 93.0 & 101 & 110 \\
\hline$P$ value & 0.74 & 0.84 & 0.71 & 0.91 & 0.09 & 0.03 & 0.01 & $<10^{-3}$ & $<10^{-3}$ & $<10^{-3}$ & $<10^{-5}$ & $<10^{-5}$ & $<10^{-5}$ & $<10^{-5}$ & $<10^{-5}$ & $<10^{-5}$ \\
\hline \multicolumn{17}{|l|}{ Equation $4^{\mathrm{w}}$} \\
\hline $\mathrm{RMSE}^{\mathrm{x}}$ & $1.10^{-3}$ & $2.10^{-3}$ & $2.10^{-3}$ & $2.10^{-3}$ & $4.10^{-3}$ & $4.10^{-3}$ & $4.10^{-3}$ & $6.10^{-3}$ & $7.10^{-3}$ & $7.10^{-3}$ & $8.10^{-3}$ & $8.10^{-3}$ & $8.10^{-3}$ & $9.10^{-3}$ & $9.10^{-3}$ & 0.01 \\
\hline \multicolumn{17}{|l|}{ Equation $6^{\mathrm{y}}$} \\
\hline$u(t)$ & -1.47 & $\ldots$ & -0.70 & 0.22 & $\ldots$ & 1.04 & $\ldots$ & 1.43 & $\ldots$ & $\ldots$ & 2.63 & $\ldots$ & $\ldots$ & $\ldots$ & $\ldots$ & $\ldots$ \\
\hline$v(t)$ & -0.10 & $\ldots$ & -0.02 & 0.35 & $\ldots$ & 0.48 & $\ldots$ & 0.51 & $\ldots$ & $\ldots$ & 0.91 & $\ldots$ & $\ldots$ & $\ldots$ & $\ldots$ & $\ldots$ \\
\hline$R^{2}$ & 0.08 & $\ldots$ & 0.03 & 0.24 & $\ldots$ & 0.70 & $\ldots$ & 0.79 & $\ldots$ & $\ldots$ & 0.83 & $\ldots$ & $\ldots$ & $\ldots$ & $\ldots$ & $\ldots$ \\
\hline$F$ & 1.13 & $\ldots$ & 0.05 & 1.63 & $\ldots$ & 29.8 & $\ldots$ & 47.9 & $\ldots$ & $\ldots$ & 65.0 & $\ldots$ & $\ldots$ & $\ldots$ & $\ldots$ & $\ldots$ \\
\hline$P$ value & 0.31 & $\ldots$ & 0.82 & 0.26 & $\ldots$ & $<10^{-4}$ & $\ldots$ & $<10^{-5}$ & $\ldots$ & $\ldots$ & $<10^{-5}$ & $\ldots$ & $\ldots$ & $\ldots$ & $\ldots$ & $\ldots$ \\
\hline \multicolumn{17}{|l|}{ Equation $7^{\mathrm{z}}$} \\
\hline $\mathrm{RMSE}^{\mathrm{x}}$ & 0.02 & $\ldots$ & 0.03 & 0.15 & $\ldots$ & 0.04 & $\ldots$ & 0.06 & $\ldots$ & $\ldots$ & 0.13 & $\ldots$ & $\ldots$ & $\ldots$ & $\ldots$ & $\ldots$ \\
\hline
\end{tabular}

u Time in days after onset of sporulation.

${ }^{v}$ Equation 2: $\ln \left[Y_{t}(d)\right]=a_{t}-b_{t} \times \ln (d)$.

${ }^{\mathrm{w}}$ Equation 4: $Y(t, d)=\exp \left\{m_{a}-\exp \left(c_{a}-f_{a} \times t\right)-\left[m_{b}-\exp \left(c_{b}-f_{b} \times t\right)\right] \times \ln (d)\right\}$.

${ }^{x}$ Calculation of roots mean square error (RMSE) is for data with lesion density between 3 and 30 lessions per $\mathrm{cm}^{2}$.

y Equation 6: $\ln \left[S_{t}(d)\right]=\mathrm{u}_{t}-\mathrm{v}_{t} \times \ln (d)$.

${ }^{\mathrm{z}}$ Equation 7: $S(t, d)=\exp \left\{m_{u}-\exp \left(d_{u}-e_{u} \times t\right)-\left[m_{v}-\exp \left(d_{v}-e_{v} \times t\right)\right] \times \ln (d)\right\}$. 
almost disappeared when spore production was related to the sporulating area (Fig. 6D). The overall spore production for the whole sporulation period varied between $0.38 \mathrm{mg} / \mathrm{mm}^{2}$ at a density of 3 lesions per $\mathrm{cm}^{2}$ and $0.28 \mathrm{mg} / \mathrm{mm}^{2}$ at 30 lesions per $\mathrm{cm}^{2}$. Daily spore production per square millimeter of sporulating area increased rapidly to a maximum and then decreased slowly toward zero. The model predicted a maximum value of approximately $0.013 \mathrm{mg} / \mathrm{mm}^{2} /$ day that was independent of lesion density. A residual density effect remained, however, in the delay at which this maximum was reached (10 days at a density of 3 lesions per $\mathrm{cm}^{2}$ and 15 days at 30 lesions per $\mathrm{cm}^{2}$ ). Spore production also lasted longer for lower lesion densities.

Effects of fertilization treatment and STB on leaf rust spore production. The nitrogen treatment had a significant effect on spore production at each date after day $11(F>13, P=0.0000)$. The cumulative spore production per lesion (Fig. 3) was not significantly different in treatment $\mathrm{N} 2$ and $\mathrm{N} 1$ throughout the sporulation period. In treatment N0, it became significantly lower than that in $\mathrm{N} 2$ after day 11 and lower than that in N1 after day 21. At the end of the sporulation period $(t=49)$, the cumulative spore production per lesion in N0 was $0.34 \mathrm{mg} / \mathrm{lesion}$ for the lowest lesion density $\left(1.7\right.$ lesions per $\mathrm{cm}^{2}$ ) and $0.13 \mathrm{mg} / \mathrm{lesion}$ for the highest lesion density (18.4 lesions per $\mathrm{cm}^{2}$ ). The cumulative spore production per lesion in treatment $\mathrm{N} 0$ was reduced by 17 to $80 \%$ (mean $=37 \%, \sigma=13 \%$ ) relative to the predicted value for treatment N1 (estimated with equation 4), and this difference was greater for the lower lesion densities.

The cumulative spore production per lesion was significantly lower in treatment $\mathrm{S}$ relative to $\mathrm{N} 1$ each date after day $11(F>12$, $P=0.0000$ ), and this difference increased with time (Fig. 7). In Figure 7 , it clearly appears that STB affected spore production directly by overlapping leaf rust lesions and indirectly by affecting the sporulation capacity of the rust lesions located in the green part of the leaves.
When considering the initial number of lesions, STB reduced the total spore production per lesion by 27 to $89 \%$ (mean $=58 \%$ and $\sigma=18 \%$ ) relative to the predicted values for treatment $\mathrm{N} 1$ (Fig. 7). Only the STB lesions growing over rust lesions accounted for a part of this reduction: this direct effect accounted for 13 to $81 \%$ (mean $=32 \%$ and $\sigma=19 \%$ ) of the total reduction in spore production. When the number of sporulating rust lesions was updated by removing those overlapped by STB, we found that the presence of STB resulted in a decrease of the sporulation capacity of the rust lesions on the green parts of the leaves: the corrected cumulative spore production per sporulating lesion was reduced by 7 to $73 \%$ (mean $=42 \%$ and $\sigma=21 \%$ ) relative to the predicted value for treatment N1 (estimated with equation 4).

Lesion size (Fig. 5) was very close in treatments N2 and N1 throughout the sporulation period (no significant differences except at day 16). In treatment N0, lesion size for densities $>4$ lesions per $\mathrm{cm}^{2}$ (Fig. 5) represented between 81 and $131 \%$ (mean $=$ $100 \%$ and $\sigma=15 \%$ ) of the predicted value for N1 (estimated with equation 7). However, lesion size was reduced by 66 and $55 \%$ for the density of 1.7 and 2 lesions per $\mathrm{cm}^{2}$ relative to the predicted value for treatment N1 (estimated with equation 7). When considering density $>4$ lesions per $\mathrm{cm}^{2}$, lesion size was not significantly different in treatments N0, N1, and N2, 21 and 28 days after onset of sporulation.

In treatment $\mathrm{S}$ (Fig. 8), the final lesion size ranged between $2.4 \mathrm{~mm}^{2}$ (at a density of 3.8 lesions per $\mathrm{cm}^{2}$ ) and $0.35 \mathrm{~mm}^{2}$ (at a density of 34.3 lesions per $\mathrm{cm}^{2}$ ). Sporulating area of rust lesions was significantly smaller than that of treatment N1 plants at each date after day 9 of sporulation $(F>6.5, P<0.02)$. Sporulating lesions on treatment $\mathrm{S}$ plants were between 0 and $72 \%$ (mean = $30 \%$ and $\sigma=20 \%$ ) smaller than the predicted values for lesions in treatment N1 (estimated with equation 7).

Carbon and nitrogen contents of uredospores. The carbon content of the spores did not vary significantly with lesion density

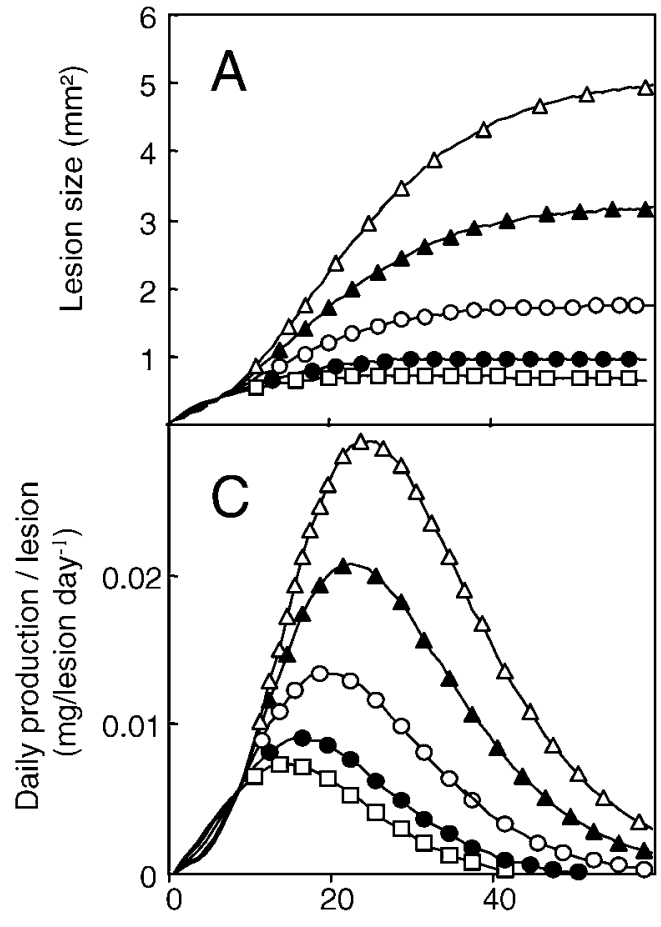

Days after onset of sporulation

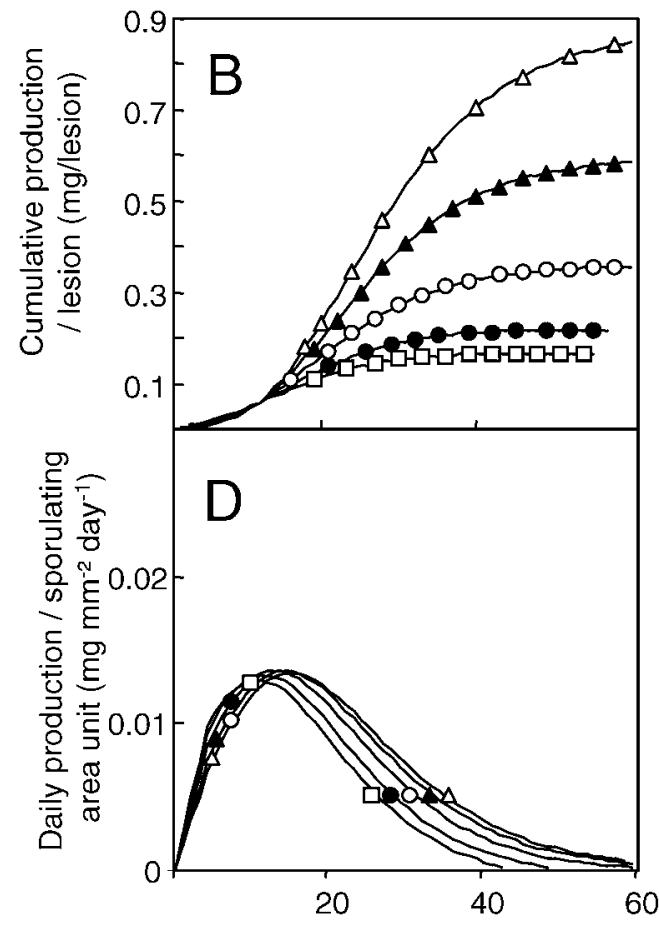

Days after onset of sporulation

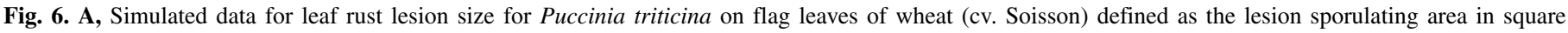

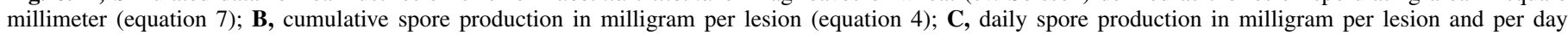

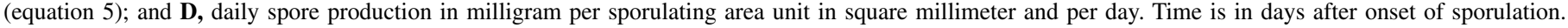

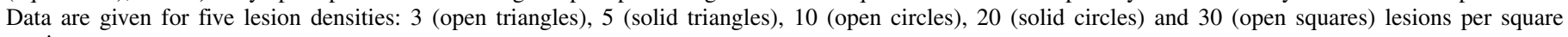
centimeter. 
( $P>0.05$ at all sampling dates). On average over the sampling dates, the spores contained $47.9 \%(\sigma=0.43)$ carbon in treatment $\mathrm{N} 1,46.4 \%(\sigma=1.20)$ in $\mathrm{S}, 47.6 \%(\sigma=0.51)$ in $\mathrm{N} 2$, and $48.7 \%$ $(\sigma=1.60)$ in N0. No significant differences were found between treatments $(P>0.05)$ except at days 14 and 21 . At day 14 , the carbon content of the spores was lower in treatment $\mathrm{S}$ relative to that in $\mathrm{N} 1$ and $\mathrm{N} 2(P=0.01)$, and at day 21 , carbon content was lower in $\mathrm{N} 2$ and $\mathrm{S}$ relative to that in N1 $(P=0.0001)$. However, these differences were all smaller than $4 \%$.

The nitrogen content of the spores was linearly related to lesion density $(P<0.01)$, except at day $4(P=0.1401)$ and $21(P=$ $0.0632)$. The effect of lesion density on spore nitrogen content was extremely limited, however, with a slope $=0.000092$ (average value for all sampling dates) and $R^{2}$ values between 0.11 and 0.45 , depending on the day. According to this relationship, spore nitrogen content should increase from 3.48 to $3.83 \%$ when lesion density increases from 1 to 40 lesions per $\mathrm{cm}^{2}$. The spore nitrogen content was lower $(P<0.01)$ in treatment N0, relative to that in $\mathrm{N} 1$ and $\mathrm{N} 2$ at sampling dates 9,14 , and 32, and was lower $(P<$ 0.01 ) in treatment $\mathrm{S}$, relative to that in N1 and N2 at sampling dates 14 and 21 . Here again, these differences were small (lower than $8 \%$ ) compared with the average values. On average over the sampling dates, the spores contained $3.68 \%(\sigma=0.11)$ nitrogen in treatment $\mathrm{N} 1,3.57 \%(\sigma=0.20)$ nitrogen in $\mathrm{S}, 3.69 \%(\sigma=0.07)$ nitrogen in $\mathrm{N} 2$, and $3.55 \%(\sigma=0.12)$ nitrogen in N0. The difference in spore nitrogen content between treatments N0 and N1 was $0.194 \pm 0.066$ (T-test, $\alpha=0.05$ ), i.e., the spore nitrogen content was reduced by $5.33 \%$ in N0 relative to that in N1.

\section{DISCUSSION}

Spore production kinetics. On adult plants (cv. Soissons), flag leaf produced a maximum of $184 \mathrm{mg}$ of spores that weighed far greater than the mean dry weight of the leaf itself $(30 \mathrm{mg})$. This suggests that in a field epidemic, the damage to the plant resulting from spore production is probably not negligible. When related to square centimeter of leaf, the weight of uredospores produced is approximately $4 \mathrm{mg}$ when the lesion density is greater than 15 lesions per $\mathrm{cm}^{2}$, which is very close to a value measured on seedlings in another study (18).

The weight of spores produced by a single lesion was strongly density dependent. According to the model established from treat-

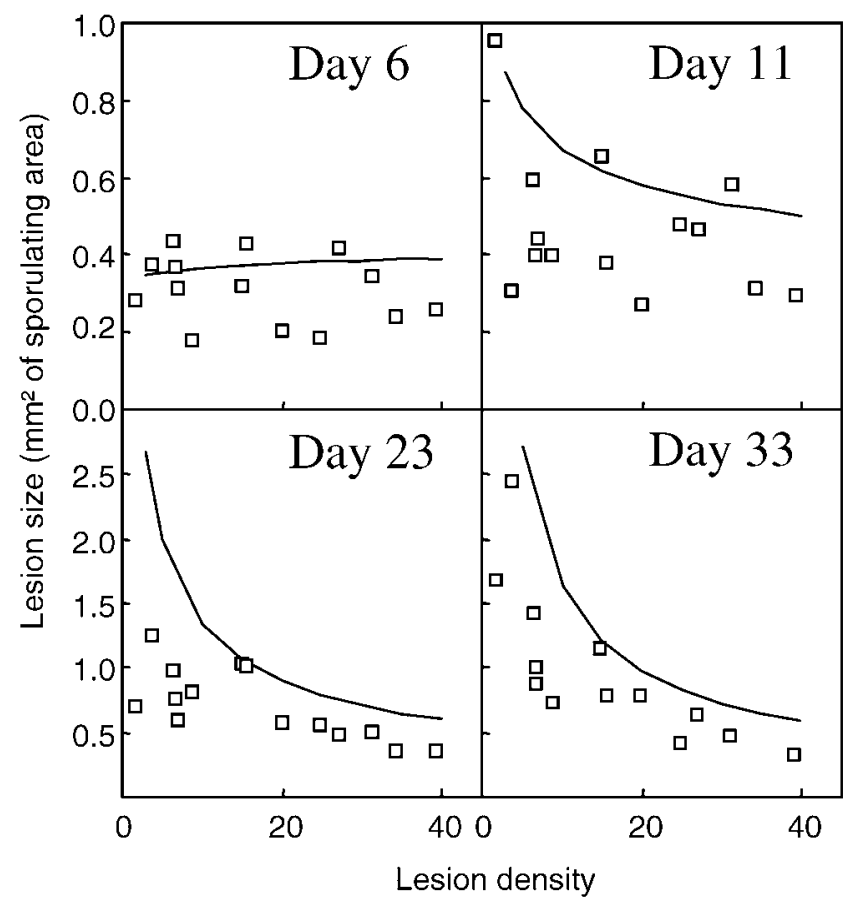

Fig. 8. Leaf rust lesion size (square millimeter), as a function of lesion density (lesions per square centimeter of leaf) and time in days after the onset of sporulation, for leaves inoculated with Puccinia triticina and Mycosphaerella graminicola (treatment S, squares). Data are compared with treatment N1 (standard-fertilization level) (continuous line, equation 7). Lesion size was defined as the sporulating area.

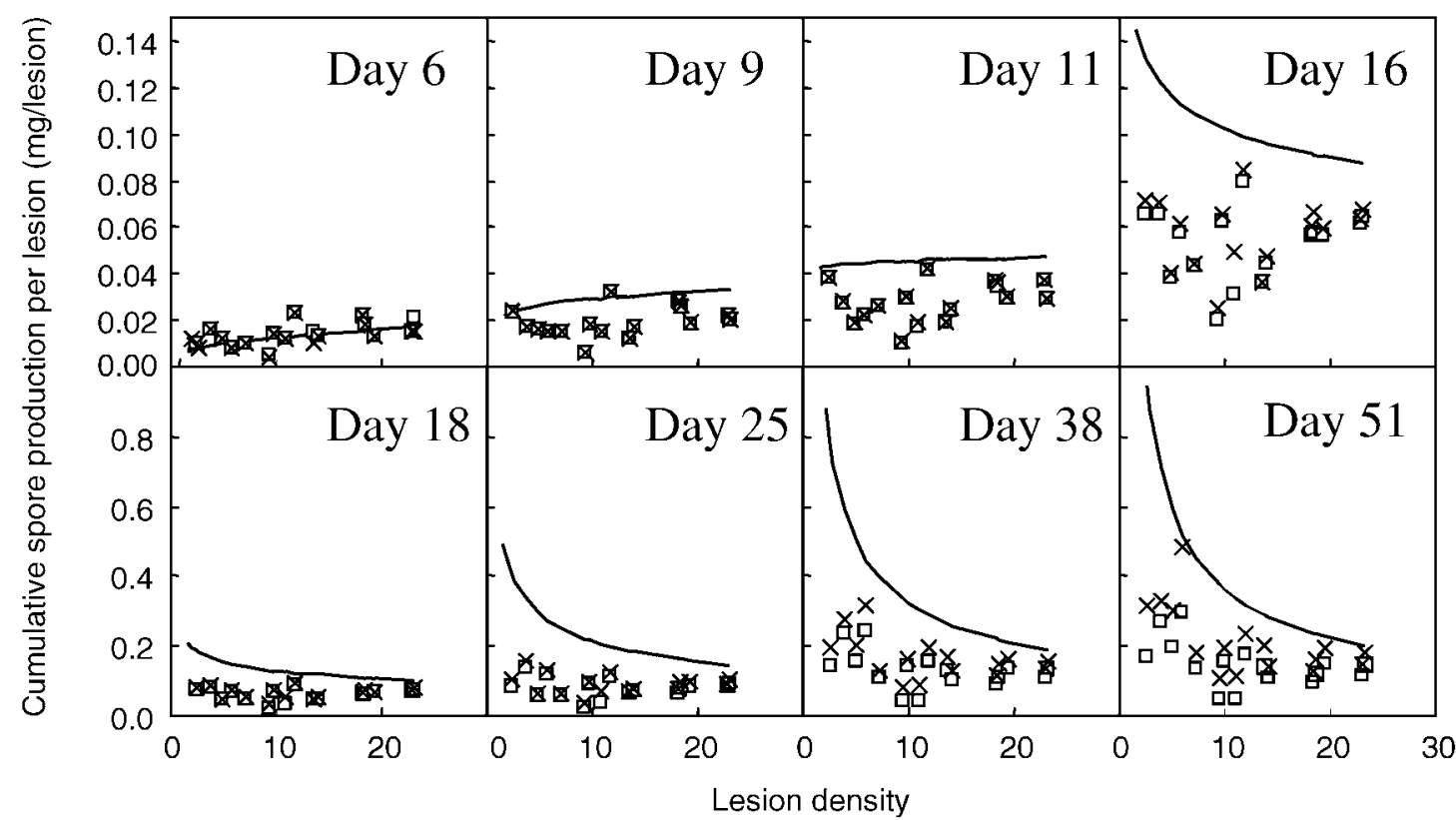

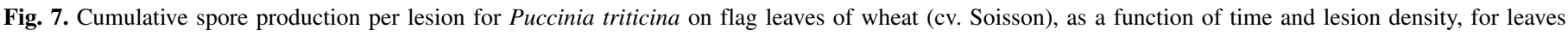

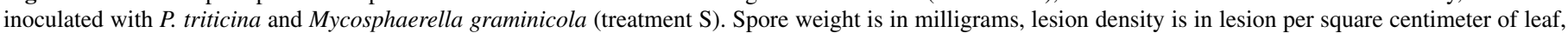

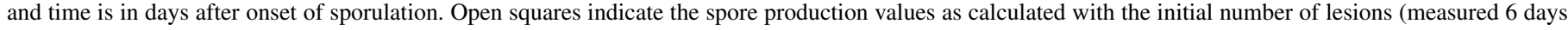

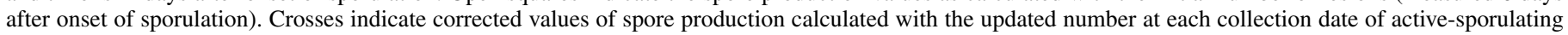

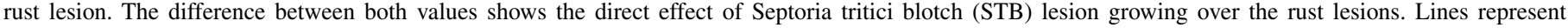

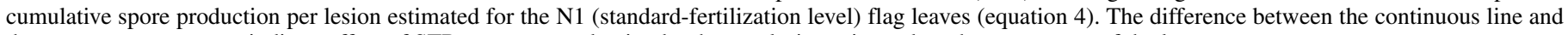
the crosses represents an indirect effect of STB on spore production by the rust lesions situated on the green parts of the leaves. 
ment N1 data (equation 4), cumulative spore production varied from $0.85 \mathrm{mg} / \mathrm{lesion}$ for a lesion density of 3 lesions per $\mathrm{cm}^{2}$ to $0.16 \mathrm{mg} / \mathrm{lesion}$ for a density of 30 lesions per $\mathrm{cm}^{2}$. Such an effect has been reported for several rust fungi $(1,15,20,23)$ and can be explained by the competition between adjacent uredia for host nutriments. These figures are comparable to those obtained on seedlings for leaf rust of wheat in a previous study (18) in which sporulation decreased from $0.93 \mathrm{mg} / \mathrm{lesion}$ at a density of $3 \mathrm{le}-$ sions per $\mathrm{cm}^{2}$ to $0.17 \mathrm{mg} / \mathrm{lesion}$ at a density of 30 lesions per $\mathrm{cm}^{2}$.

The sporulation pattern per lesion on flag leaves, in milligrams of spores per lesion per day, was similar to those obtained in experiments performed with seedlings $(16,18,20)$ : spore production per lesion increased to a maximum and then decreased slowly toward zero at all lesion densities, the sporulation period was longer at lower lesion densities and the maximum value for daily spore production per lesion was greater. However, on adult plants, sporulation started more slowly than on primary leaves (18) but lasted longer (60 days compared with 35 days). This was also reported by Tomerlin et al. (22) and should be taken into account when evaluating the survival and dispersal capacity of leaf rust in the field. The maximum spore production in flag leaves was $0.028 \mathrm{mg} / \mathrm{lesion} /$ day at the density of 3 lesions per $\mathrm{cm}^{2}$, compared with $0.043 \mathrm{mg} /$ lesion/day in seedlings (18).

Increasing lesion density greatly reduced lesion size. According to the lesion size model (equation 7), the maximal size of a lesion was $5 \mathrm{~mm}^{2}$ at a density of 3 lesions per $\mathrm{cm}^{2}$ and only $0.69 \mathrm{~mm}^{2}$ at the high density of 30 lesions per $\mathrm{cm}^{2}$. These figures are comparable to those obtained on wheat primary leaves in a previous study (18), in which lesion size decreased from $4 \mathrm{~mm}^{2}$ for a density of 3 lesions per $\mathrm{cm}^{2}$ to 0.64 for a density of 30 lesions per $\mathrm{cm}^{2}$.

Most of the effect of density on spore production per lesion was accounted for by lesion size: when related to the sporulating area, spore production became largely independent of lesion density. A residual density effect remained, however, since the total weight of spores produced per square millimeter of sporulating area was slightly lower for high lesion densities than for low lesion densities. According to our model, increasing lesion density reduces the sporulation period without changing the maximal spore production. This could be interpreted as a density effect altering the lesion life span. However, the lesion size model did not simulate the decrease in sporulating surface due to the lesion necrosis that was observed toward the end of the sporulation period. Thus, at the end of the sporulation period, the spore production per sporulating area unit was probably underestimated.

The pattern of spore production per sporulating area unit was comparable to that obtained with seedlings (18) but had a lower maximal value and a longer sporulation period. The maximum spore production in flag leaves was $0.013 \mathrm{mg}$ per $\mathrm{mm}^{2}$ of sporulating area and per day, compared with $0.033 \mathrm{mg}$ in seedlings (18). There are several possible explanations to account for these differences: climatic conditions were more variable in the glasshouse compared with a growth chamber; adult leaves could possess a greater resistance level to the development of lesions; and flag leaves live longer (200 days) relative to primary leaves (60 days) and thus allow a better availability of host nutriments over time. Despite such differences, it is remarkable that the total spore production per lesion, the density effect, and the sporulation pattern per sporulating area unit measured in flag leaves were so similar to those obtained in primary leaves (18).

Spore production can be evaluated by counting (20) or weighing (18) the spores. The choice of the method mainly depends on practical constraints. For a large number of samples, we found that weighing the spores was much more efficient. Moreover, this allowed us to measure the carbon and nitrogen content on the same samples, whereas spores generally have to be put into suspension to be counted. The spore weight (as measured in the current experiment) and number (as measured with a particle counter,
Coulter Counter ZM2; Beckman, Paris) can be related by (C. Lannou, unpublished data $)$ number $=203410 \times$ weight $\left(R^{2}=\right.$ $0.99)$

Leaf nitrogen status and spore production. In this work, the host fertilization level strongly affected spore production by leaf rust. A similar effect has been described for Erysiphe graminis $\mathrm{f}$. sp. hordei (12). No differences were found however, in spore production or lesion size between treatments N1 and N2, which suggests a threshold effect. In treatment N0, relative to N1, spore production per lesion was reduced but the lesion size was unaffected, except at the very low lesion densities. The reduced spore production under the conditions of limited nitrogen availability could then be attributed to a less efficient sporulation, not to a smaller lesion size.

In treatment $\mathrm{N} 0$, relative to $\mathrm{N} 1$, the leaf nitrogen content at the end of the experiment was reduced by $53.8 \%$, but the spore nitrogen content was reduced by only $5.3 \%$ whereas, the cumulative spore production per lesion was reduced by 17 to $80 \%$, depending on lesion density (average reduction $=37 \%$ ). Thus, in treatment N0, plants produced fewer spores than they did in N1, but the nitrogen contents of the spores were almost similar in both treatments. This suggests that the nitrogen content of the spores is very conservative. Spores produced in treatments N2, N1, and S contained in average $3.7 \%$ nitrogen, compared with $3.5 \%$ in N0. In another experiment (18), the spores contained $4 \%$ nitrogen when produced by standard seedlings and $3.4 \%$ when produced by nitrogen-deficient seedlings.

Our fertilization treatments altered the amount of nitrogen available for the plant but changed also the amount of potassium $(\mathrm{K})$ and phosphate $(\mathrm{P})$. $\mathrm{P}$ and $\mathrm{K}$ contents might also have influenced spore production.

The difference in spore production per lesion between treatments N0 and N1 was greater for lower lesion densities. This was probably because the nitrogen deficiency in N0 was greater at the maximum spore production for low lesion densities. Indeed, the sporulation kinetics was slower for lower lesion densities and the difference in nitrogen content between N0 and N1 increased with time: the flag leaf nitrogen content in treatment N1 was not significantly different than that in N0 on the day before inoculation, but it was much lower at the end of the sporulation period.

In our experiment, the three nitrogen treatments resulted in an average of 0.18 (N0), 0.19 (N1), and 0.24 (N2) $\mathrm{mg}$ of nitrogen per $\mathrm{cm}^{2}$ in flag leaves around heading. These relatively close values were unexpected considering the large differences in the amounts of fertilizer applied. An explanation is that the plants with a lower-nitrogen fertilization produced fewer tillers and smaller leaves. In the field, nitrogen starved wheat plants first react by reducing the number of tillers and the leaf surface area, and then by reducing the leaf nitrogen content (10). The flag leaf nitrogen content at flowering is usually between 0.20 and $0.30 \mathrm{mg}$ per $\mathrm{cm}^{2}$ of leaf in northern France, depending on the nitrogen fertilization used (10).

Effect of STB on uredospore production. STB impaired the production of leaf rust uredospores so that spore production per lesion by the leaves inoculated with $P$. triticina and $M$. graminicola was reduced by 30 to $80 \%$ depending on the leaves. This reduction was partly caused by the STB necrosis growing over the sporulating rust lesions, but resulted also from an indirect effect on rust lesions located in the green part of the leaves. This indirect effect caused a decrease of $42 \%$ (between 7 and $73 \%$ depending on lesion density) in the spore production per lesion and was especially strong for the lowest lesion densities, probably because the dynamics of spore production were delayed relative to high lesion densities. For low densities, the maximum spore production occurred when STB was already largely established on the leaves. The relative localization of rust and STB lesions on the leaves could explain the relatively high variation in the level of spore production in treatment $\mathrm{S}$. 
On leaves infected with STB, the sporulating rust lesions were also 0 to $72 \%$ smaller than the predicted values for treatment $\mathrm{N} 1$ and they varied greatly in size, with no clear relation to rust lesion density. Similarly, the decrease in the number of sporulating rust lesions due to STB lesion growth varied from one leaf to another. These effects probably depended on the number, size, and distribution of the STB lesions on the leaves.

In treatment $\mathrm{S}$, leaves were fertilized as $\mathrm{N} 1$, but we observed that the spores contained slightly less carbon than in other treatments, although the difference was not significant. Moreover, leaf carbon content of the treatment $\mathrm{S}$ plants at the end of the sporulation period was lower than that of the N1 and N2 plants. The rust lesions could then have suffered from a lack of carbon, perhaps because STB altered the leaf functions.

Coupling epidemic and crop growth models is a promising way for improving the understanding and prediction of yield reduction $(5,13,17)$. The quantitative relationships between injuries and damage to the plant have already been established for several pathosystem $(2,4,9,17)$, but precise identification of the link points where the plant and the pathogens interact is still needed. Our current results evaluate the loss of biomass by leaf rust spores under a biotic (STB) and an abiotic stress (fertilization deficiency). They suggest that sporulating area could be a pertinent variable for linking leaf rust epidemic and crop growth models because leaf rust spore production per sporulating unit area is independent of lesion density and because the effect of leaf rust on photosynthesis is proportional to the diseased surface area (21).

\section{LITERATURE CITED}

1. Baart, P. G. J., Parlevliet, J. E., and Limburg, H. 1991. Effects of infection density on the size of barley and wheat leaf rust colonies before and on the size of uredia after the start of sporulation. J. Phytopathol. 131:59-64.

2. Bassanezi, R. B., Amorim, L., Bergamin Filho, A., Hau, B., and Berger, R. D. 2001. Accounting for photosynthetic efficiency of bean leaves with rust, angular leaf spot and anthracnose to assess crop damage. Plant Pathol. 50:443-452.

3. Bastiaans, L. 1991. Ratio between virtual and visual lesion size as a measure to describe reduction in leaf photosynthesis of rice due to leaf blast. Phytopathology 81:611-615.

4. Beasse, C., Ney, B., and Tivoli, B. 2000. A simple model of pea (Pisum sativum) growth affected by Mycosphaerella pinodes. Plant Pathol. 49:187-200.

5. Boote, K. J., Jones, J. W., Mishoe, J. W., and Berger, R. D. 1983. Coupling pests to crop growth simulators to predict yield reductions. Phytopathology 73:1581-1587.
6. Cohen, Y., and Rotem, J. 1970. The relationship of sporulation to photosynthesis in some obligatory and facultive parasites. Phytopathology 60:1600-1604.

7. Dumas, J. B. 1831. Procédés de l'analyse organique. Ann. Chim. Phys. 247:198-213.

8. Eyal, Z., Clifford, B. C., and Caldwell, R. M. 1968. A settling tower for quantitative inoculation of leaf blades of mature small grain plants with urediospores. Phytopathology 58:530-531.

9. Garry, G., Jeuffroy, M. H., Ney, B., and Tivoli, B. 1998. Effects of Aschochyta blight on the decrease in photosynthetizing leaf area and the reduction of photosynthetic efficiency by green leaf area of dried-pea. Plant Pathol. 47:473-479.

10. Girard, M. L. 1997. Modélisation de l'accumulation de biomasse et d'azote dans les grains de blé tendre d'hiver (Triticum aestivum); Simulation de leur teneur en protéines à la récolte, INA-PG, INRA.

11. Imhoff, M. W., Leonard, K. J., and Main, C. E. 1982. Patterns of bean rust lesion size increase and spore production. Phytopathology 72:441446.

12. Jensen, B., and Munk, L. 1997. Nitrogen induced changes in colony density and spore production of Erysiphe graminis f. sp. hordei on seedlings of six spring barley cultivars. Plant Pathol. 46:191-202.

13. Johnson, K. B., and Teng, P. S. 1990. Coupling a disease progress model for early blight to a model of potato growth. Phytopathology 80:416-425.

14. Kardin, M. K., and Groth, J. V. 1989. Density-dependent fitness interactions in the bean rust fungus. Phytopathology 79:409-412.

15. Leonard, K. J. 1969. Factors affecting rates of stem rust increase in mixed plantings of susceptible and resistant oat varieties. Phytopathology 59:1845-1850.

16. Mehta, Y. R., and Zadoks, J. C. 1970. Uredospore production and sporulation period of Puccinia recondita $\mathrm{f}$. sp. triticina on primary leaves of wheat. Neth. J. Plant Pathol. 76:267-276.

17. Pinnschmidt, H. O., Batchelor, W. D., and Teng, P. S. 1995. Simulation of multiple species pest damage in rice using CERES-rice. Agric. Syst. 48:193-222.

18. Robert, C., Bancal, M. O., and Lannou, C. 2002. Wheat leaf rust uredospore production and carbon and nitrogen export in relation to lesion size and density. Phytopathology 92:762-768.

19. Rouse, D. I., MacKenzie, D. R., and Nelson, R. R. 1984. Density dependent sporulation of Erysiphe graminis f. sp. tritici. Phytopathology 74:1176-1180.

20. Sache, I., and De Vallavieille-Pope, C. 1993. Comparison of the wheat brown and yellow rusts for monocyclic sporulation and infection processes, and their polycyclic consequences. J. Phytopathol. 138:55-65.

21. Shtienberg, D. 1992. Effects of foliar diseases on gas exchange processes: A comparative study. Phytopathology 82:760-765.

22. Tomerlin, J. R., Eversmeyer, M. G., Kramer, C. L., and Browder, L. E. 1983. Temperature and host effects on latent and infectious periods and on urediniospore production of Puccinia recondita f. sp. tritici. Phytopathology 73:414-419.

23. Yarwood, C. E. 1961. Uredospore production by Uromyces phaseoli. Phytopathology 51:22-27.

24. Zadoks, J. C., Chang, T. T., and Konzak, C. F. 1974. A decimal code for the growth stages of cereals. Weed Res. 14:415-421. 